\title{
A Misdiagnosed Complication of a Metal-on-Metal Total Hip Arthroplasty
}

\author{
Az-Eddine Djebara ${ }^{D},{ }^{1}$ Cédric Joseph, ${ }^{2}$ Florence Rousseau, ${ }^{3}$ Benoit Brunschweiler, ${ }^{1}$ \\ and Patrice Mertl ${ }^{1}$
}

\author{
${ }^{1}$ Department of Orthopaedics and Traumatology, CHU Amiens Picardie, 80480 Amiens, France \\ ${ }^{2}$ Department of Infectious Diseases, CHU Amiens Picardie, 80480 Amiens, France \\ ${ }^{3}$ Department of Bacteriology, CHU Amiens Picardie, 80480 Amiens, France
}

Correspondence should be addressed to Az-Eddine Djebara; azeddine.djebara@gmail.com

Received 21 September 2017; Accepted 26 February 2018; Published 15 March 2018

Academic Editor: Paul E. Di Cesare

Copyright (c) 2018 Az-Eddine Djebara et al. This is an open access article distributed under the Creative Commons Attribution License, which permits unrestricted use, distribution, and reproduction in any medium, provided the original work is properly cited.

\begin{abstract}
Introduction. The enterobacterial genus Yersinia includes a number of human pathogens. Large-diameter, metal-on-metal prostheses are no longer used because of their high failure rate. Here, we describe the first case of Yersinia enterocolitica infection of a metal-on-metal total hip arthroplasty. Clinical Examination. A metal-on-metal prosthesis failed ten years after implantation. After surgical revision, bacteriological testing revealed the presence of a pathogenic strain of Yersinia enterocolitica. Combination antibiotic therapy resulted in a favorable clinical outcome. Discussion. Three cases of hip arthroplasty infected with Yersinia enterocolitica have been described in the literature. The present case is the first infection of a metal-onmetal total hip arthroplasty. We suggest that the risk of infection is increased by the release of metal wear particles and their influence on the surrounding tissue. Conclusion. When a large-diameter, metal-on-metal total hip arthroplasty fails, the known complications associated with this type of prosthesis should not deter the physician from screening for an infectious process that requires specific treatment.
\end{abstract}

\section{Introduction}

Three members of the enterobacterial genus Yersinia (Yersinia enterocolitica, Yersinia pestis, and Yersinia pseudotuberculosis) are human pathogens. Yersinia enterocolitica $(Y E)$ is occasionally responsible for acute intestinal infections (especially in young patients) with secondary joint and dermatological symptoms. The digestive symptoms usually disappear after 1 to 3 weeks. In immunosuppressed patients, however, the infection can persist and cause bacteraemia. The joint symptoms usually appear two weeks after the digestive signs and are usually due to aseptic, reactive arthritis. A few cases of septic arthritis with Yersinia in native joints and on prostheses have been described in the literature [1-3]. Here, we report on the first case of $Y E$ infection of a large-diameter, metal-on-metal total hip arthroplasty (THA).

\section{Clinical Findings}

An 85-year-old patient received regular checkups for a left, large-diameter, metal-on-metal THA (a Contact ${ }^{\circledR}$ stem and a Durom ${ }^{\circledR}$ cup) implanted 11 years previously. His medical history included right THA in 1989 (revised in 1995) and mucosa-associated lymphoid tissue lymphoma of the left eye (treated with surgery and chemotherapy). Laboratory assays showed abnormally high but stable serum levels of chromium $(33 \mathrm{nmol} / \mathrm{L})$ and cobalt $(73 \mathrm{nmol} / \mathrm{L})$ during follow-up (normative values: $<10 \mathrm{nmol} / \mathrm{L}$ for both metals). Following the onset of severe pain in the left hip, imaging (X-rays, ultrasound, and CT) revealed a calcified pseudocyst (Figure 1), a frequent complication of metal-on-metal prostheses [4]. The serum chromium and cobalt levels had risen to $71 \mathrm{nmol} / \mathrm{L}$ and $145 \mathrm{nmol} / \mathrm{L}$, respectively (Figure 2), and appeared to be correlated with the patient's pain levels, although the precise 

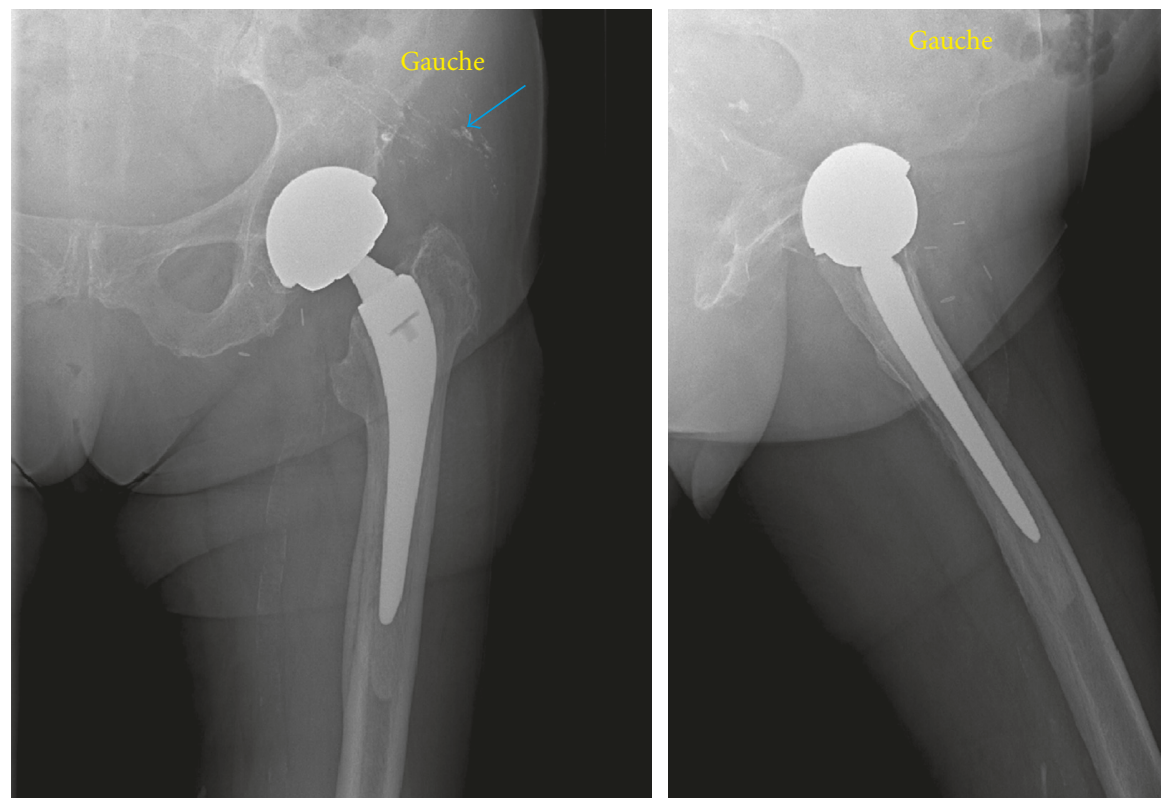

FIgURE 1: Left metal-on-metal THA with a pseudocyst.

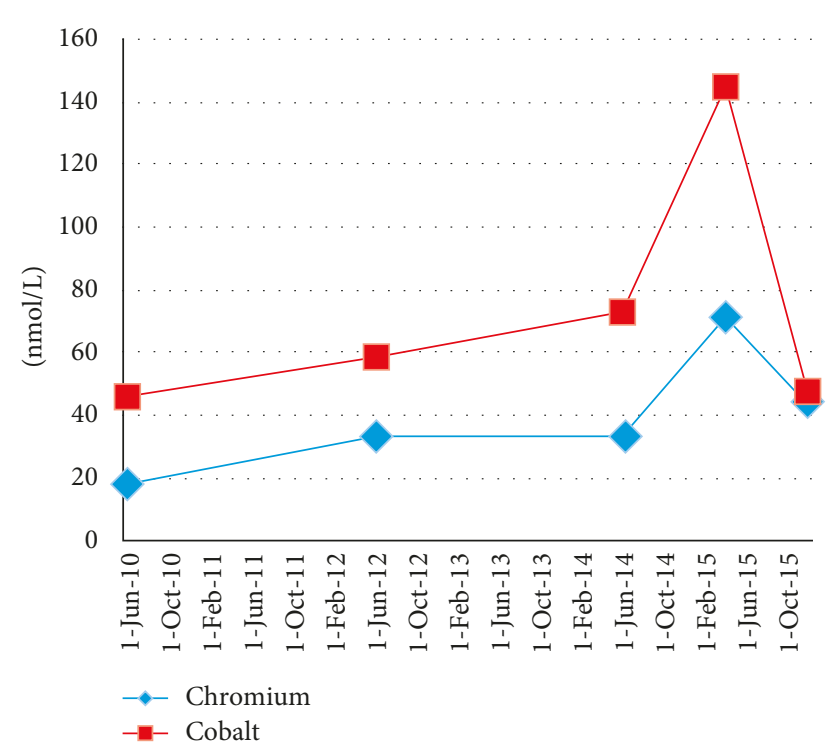

Figure 2: Change in serum chromium and cobalt levels over time.

cause of the pain remained unclear [5]. The pain intensity continued to increase, whereas the serum C-reactive protein level was stable $(110 \mathrm{mg} / \mathrm{l})$. Three months later, endoscopy exploration of the digestive tract revealed a hiatal hernia. Biopsies of the fundus and duodenum were negative. Colonoscopy revealed sigmoid diverticulitis, and two polyps were removed. The patient was reexamined 6 months later. A hip $\mathrm{X}$-ray showed marked endosteal osteolysis around the stem (Figure 3). The serum chromium and cobalt levels had fallen to $43 \mathrm{nmol} / \mathrm{L}$ and $48 \mathrm{nmol} / \mathrm{L}$, respectively. We decided to replace the prosthesis and proceeded to implant a cementless stem and a dual mobility cup (Figure 4). During surgery, we discovered a voluminous pseudocyst containing milky fluid and encapsulated by a pseudomembrane. Eight deep-tissue samples were sent for histopathological assessment and bacteriological testing. The results confirmed the presence of inflammation around the pseudosynovial membrane, with a macrophage reaction around metal wear particles.

\section{Bacteriology}

Direct examination of Gram-stained samples was negative. After 48 hours of culture on selective growth media and colony picking, mass spectrometry confirmed the presence of $Y E$. In parallel, Gram staining revealed small, Gram-negative, ureasepositive bacilli. Antibiotic susceptibility testing showed that the bacterium was sensitive to third-generation cephalosporins, aminoglycosides, trimethoprim + sulfamethoxazole, and tetracycline, intermediate for quinolones, and resistant to ampicillin, amoxicillin + clavulanic acid, ureidopenicillins, and carboxypenicillins. The bacterium was later sent to the French National Yersinia Reference Centre (Pasteur Institute, Paris) for pathogenicity screening; biochemical tests and serotyping confirmed that the $Y E$ strain was potentially pathogenic in humans. Following a multidisciplinary team meeting (with the surgeon, an infectious disease specialist, and a medical biologist), probabilistic, broad-spectrum, dual-antibiotic therapy was initiated immediately after replacement of the implant (cefepime and vancomycin for 2 days, followed by trimethoprim + sulfamethoxazole $800 \mathrm{mg}$ three times a day and ceftriaxone $1.5 \mathrm{~g}$ twice a day for 6 weeks).

\section{Clinical Outcome}

The postoperative course was uneventful, and the patient was able to walk immediately. He was discharged from hospital nine days after surgery. At the time of writing (six months later), he is able to walk unaided at home, the scar is clean, and there are no signs of osteolysis or displacement of the implant on X-rays. One month after the discontinuation 

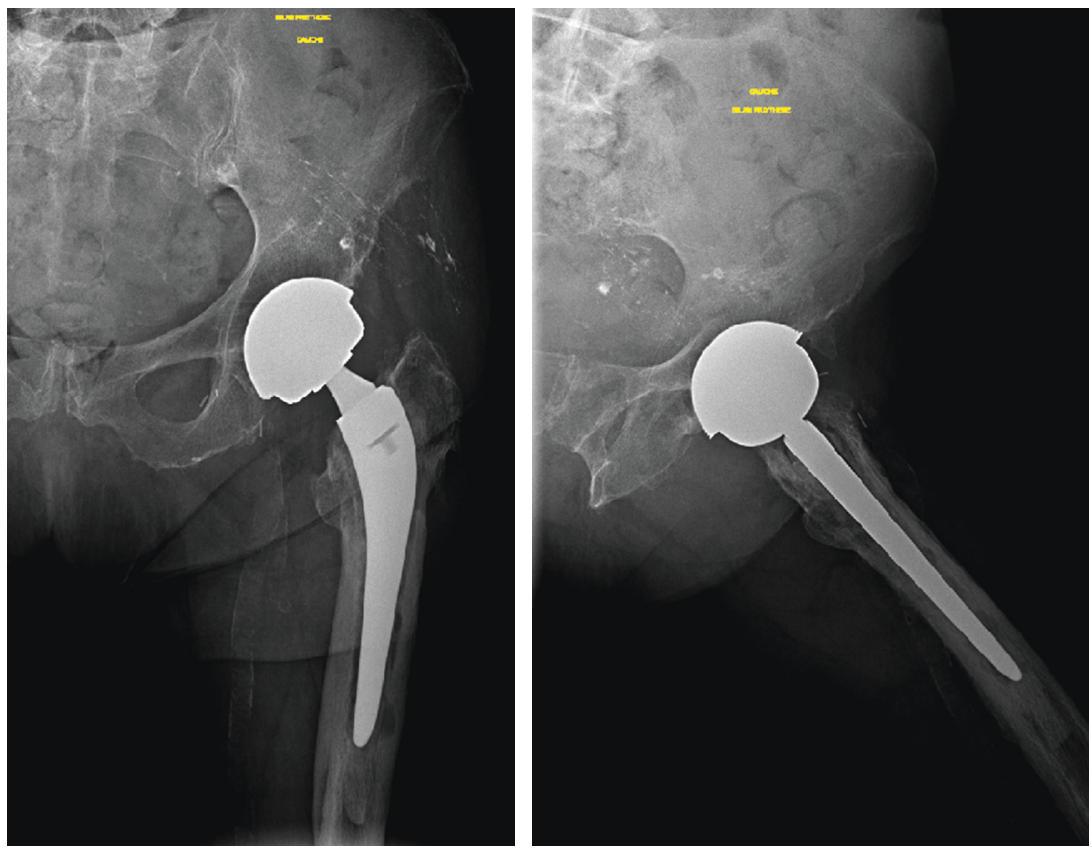

Figure 3: Endosteal osteolysis around the stem.
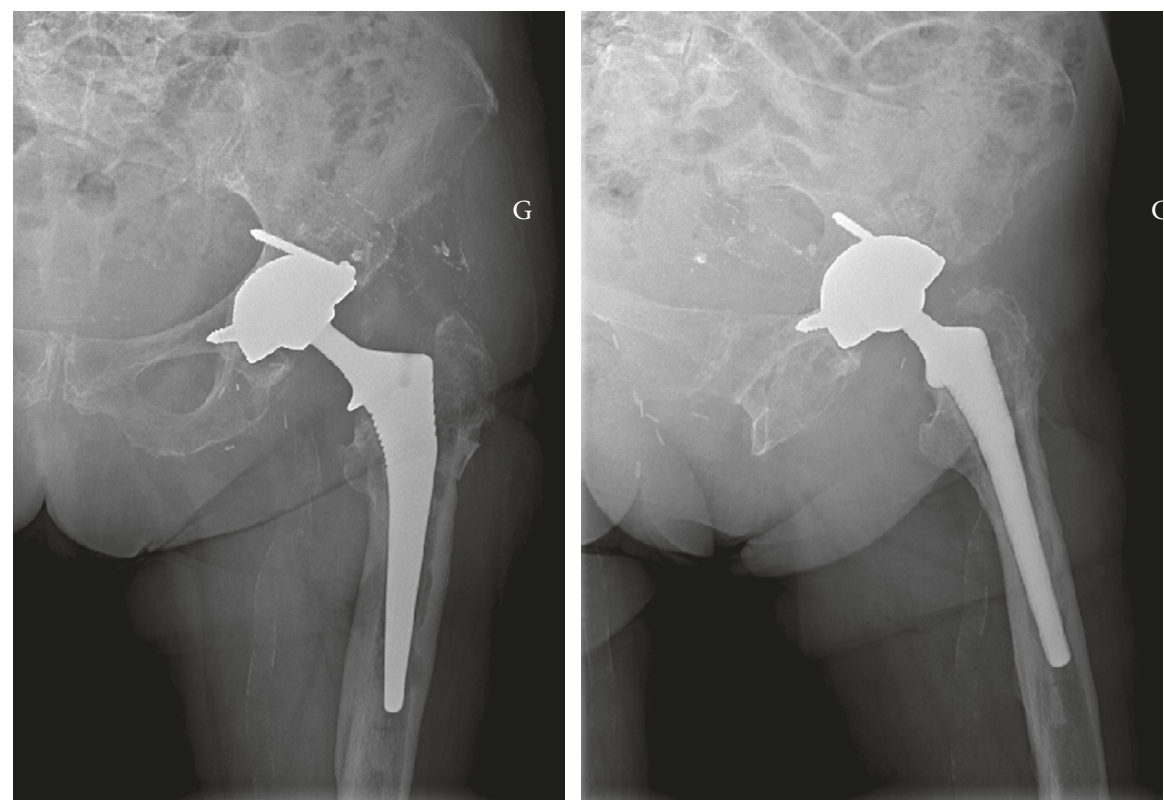

Figure 4: Postoperative X-ray.

of antibiotic therapy, the patient was free of pain, and his serum CRP level had normalized.

\section{Discussion}

Yersinia infections outside the digestive tract are rare but usually result from blood dissemination from the gut in immunocompromised subjects [6]. There are very few studies of septic complications of metal-on-metal THA $[7,8]$. Three cases of THA infection with $Y E$ have been described in the literature. Hansen et al. reported the first case of septic loosening of an Austin Moore prosthesis implanted with an indication of osteonecrosis [1]. Hougaard and Søgaard described a chronic THA infection ten years after surgery [2]. Jean-Pierre et al. reported on a second case of septic loosening [3]. Although friction torque appears to be associated with an abnormally high infectious complication rate, it is difficult to establish a clear correlation. It has been hypothesized that high concentrations of metal wear particles, metal ions, and corrosion products have molecular effects on the surrounding soft tissues and thus change the local environment $[9,10]$ Paradoxically, it seems that the 
Co-Cr particles released into dynamic growth media by metal-on-metal THAs inhibit biofilm formation in some germs-making them more vulnerable to clearance by the immune system or antibiotics [11]. In the present case, we suspect that endoscopic investigation of the digestive tract during the patient's course of chemotherapy caused blood dissemination of the bacteria. However, in an interview, the patient did not recall experiencing any digestive problems in the weeks preceding surgery. The onset of this infection (discovered fortuitously during surgery) cannot therefore be determined with accuracy.

\section{Conclusion}

When a large-diameter, metal-on-metal THA fails, the known complications associated with this type of prosthesis should not deter the physician from screening for an infectious process. A YE infection may be present and will require specific antibiotic treatment, along with surgical revision.

\section{Conflicts of Interest}

The authors declare that they have no conflicts of interest.

\section{References}

[1] W. Hansen, M. El Doualy, P. Putz, and Y. Glupczynski, "Infection de prothèse de hanche à Yersinia enterocolitica," Médecine et Maladies Infectieuses, vol. 19, no. 10, pp. 459-461, 1989.

[2] K. Hougaard and P. Søgaard, "Yersinia enterocolitica coxitis after hip replacement: a case report," Acta Orthopaedica Scandinavica, vol. 61, no. 4, pp. 364-366, 1990.

[3] H. Jean-Pierre, H. Darbas, G. Boyer, and C. Carrière, "Infection d'une prothèse de hanche à Yersinia enterocolitica: deuxième cas," Médecine et Maladies Infectieuses, vol. 22, no. 11, pp. 941-942, 1992.

[4] H. Migaud, S. Putman, A. Combes et al., "Metal-on-metal bearing: is this the end of the line? We do not think so," HSS Journal ${ }^{\circledR}$, vol. 8, no. 3, pp. 262-269, 2012.

[5] J.-F. Lardanchet, J. Taviaux, D. Arnalsteen, A. Gabrion, and P. Mertl, "One-year prospective comparative study of three large-diameter metal-on-metal total hip prostheses: serum metal ion levels and clinical outcomes," Orthopaedics \& Traumatology: Surgery \& Research, vol. 98, no. 3, pp. 265-274, 2012.

[6] T. Cover and R. Aber, "Yersinia enterocolitica," New England Journal of Medicine, vol. 321, no. 1, pp. 16-24, 1989.

[7] P. Mertl, O. Boughebri, E. Havet, P. Triclot, J.-F. Lardanchet, and A. Gabrion, "Large diameter head metal-on-metal bearings total hip arthroplasty: preliminary results," Orthopaedics \& Traumatology: Surgery \& Research, vol. 96, no. 1, pp. 14-20, 2010.

[8] J. Munro, B. Masri, C. Duncan, and D. Garbuz, "High complication rate after revision of large-head metal-on-metal total hip arthroplasty," Clinical Orthopaedics and Related Research $^{\circledR}$, vol. 472, no. 2, pp. 523-528, 2014.

[9] D. Saragaglia, B. Belvisi, B. Rubens-Duval, R. Pailhé, R. Rouchy, and R. Mader, "Clinical and radiological outcomes with the Durom acetabular cup for large-diameter total hip arthroplasty: 177 implants after a mean of 80 months,"
Orthopaedics \& Traumatology: Surgery \& Research, vol. 101, no. 4, pp. 437-441, 2015.

[10] C. Wyles, R. Van Demark, R. Sierra, and R. Trousdale, "High rate of infection after aseptic revision of failed metal-on-metal total hip arthroplasty," Clinical Orthopaedics and Related Research $^{\circledR}$, vol. 472, no. 2, pp. 509-516, 2014.

[11] A. Hosman, H. Van Der Mei, B. Sjoerd, R. Kuijer, H. Busscher, and D. Neut, "Influence of Co-Cr particles and Co-Cr ions on the growth of staphylococcal biofilms," International Journal of Artificial Organs, vol. 34, no. 9, pp. 759-765, 2011. 


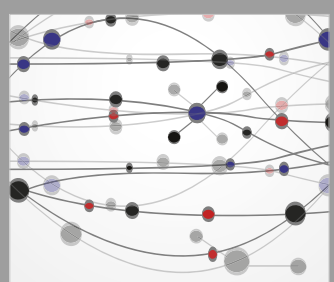

The Scientific World Journal
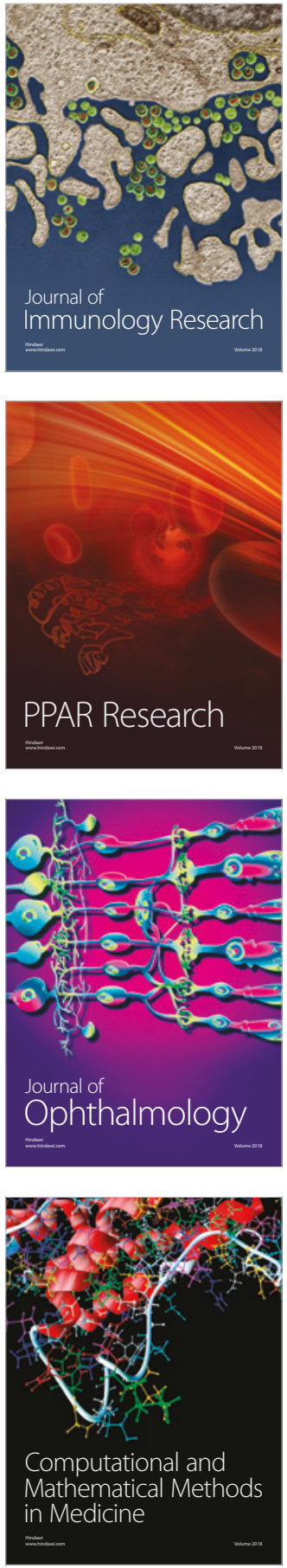

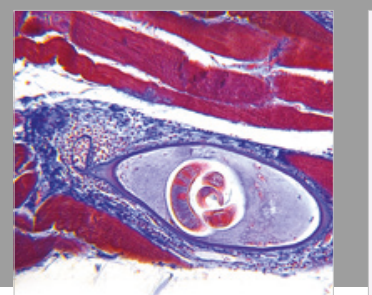

Gastroenterology Research and Practice

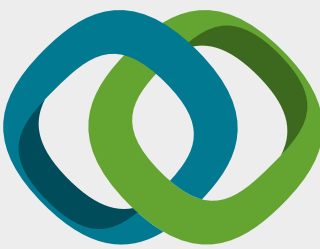

\section{Hindawi}

Submit your manuscripts at

www.hindawi.com
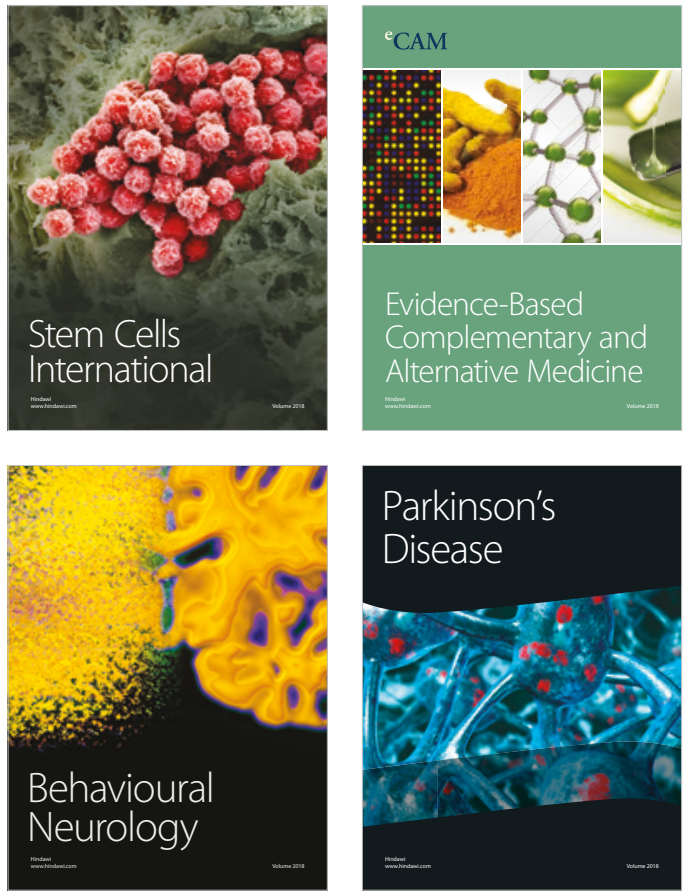

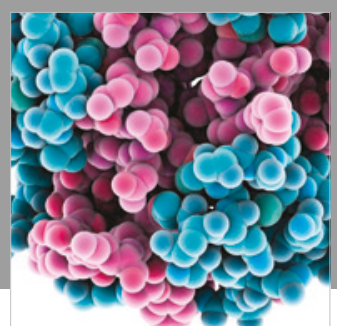

ournal of

Diabetes Research

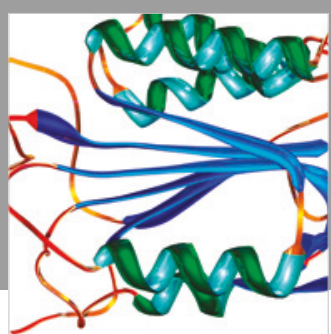

Disease Markers
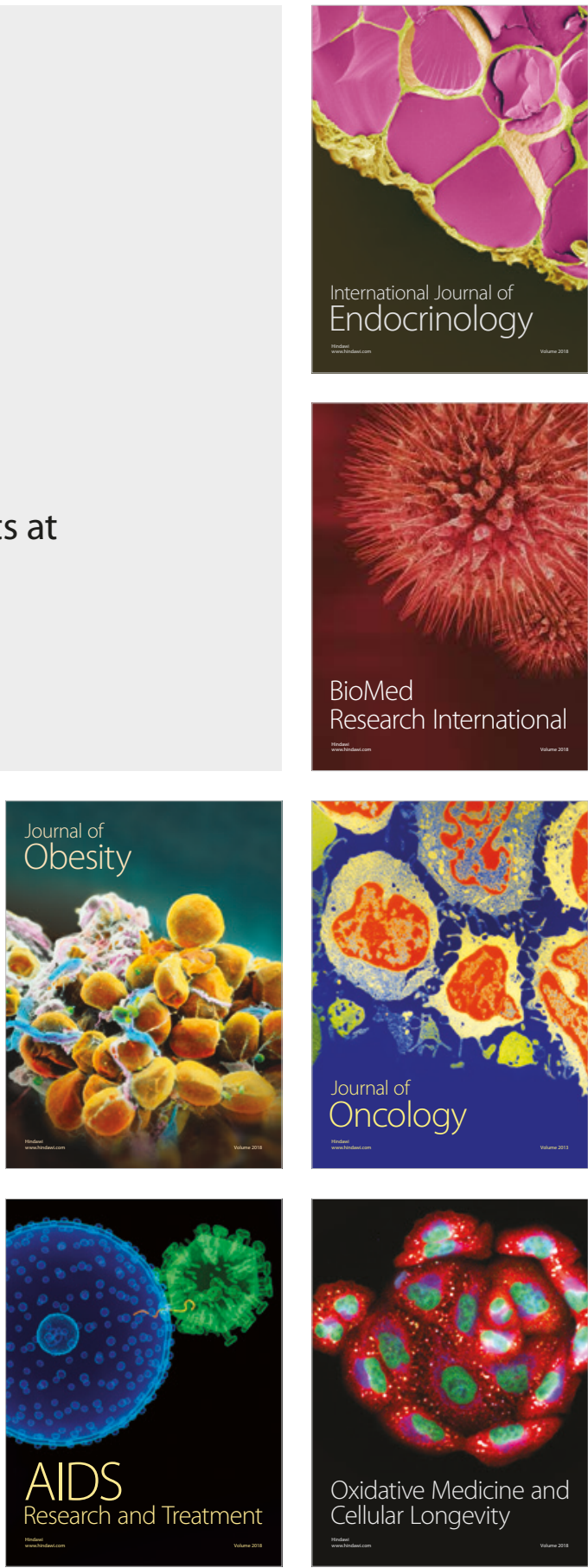